\title{
Kansei Mediated Entertainment
}

\author{
Ben Salem ${ }^{1 *}$, Matthias Rauterberg ${ }^{2}$, Ryohei Nakatsu ${ }^{1}$ \\ ${ }^{1}$ School of Science and Technology, Kwansei Gakuin University, Sanda, Japan \\ ${ }^{2}$ Department of Industrial Design, Eindhoven University of Technology, Eindhoven, The Netherlands \\ * corresponding author: mail@bsalem.info
}

\begin{abstract}
We present an extension of Kansei mediated communication in the field of entertainment. We propose to do so by implementing Cultural Computing concept and enriching it with Kansei Mediated Interaction. We present some inspiration for our approach in terms of culture and then discuss them. We relate our work to the Western and to the Eastern world. Thus we use cultural examples from England, France, Japan and China. Finally, we propose as a new direction for HCI, cultural computing with its related paradigm we call Kansei Mediated Interaction. Finally we propose Kansei Mediated Entertainment as a direction merging of Kansei and entertainment.
\end{abstract}

Keywords: cultural computing, Kansei mediation, unconscious, entertainment

\section{Introduction}

From a historical perspective, Human-Computer Interaction (HCI) has evolved over more than five decades. Although the history of HCI is rich and complex, within the scope of this paper we will summarise some of the key milestones (see Fig. 1). The history of HCI stretches back to the 60s. Originally it was about Man-Machine Interaction and the emergence of the Personal Computing (PC) paradigm. In the $80 \mathrm{~s}$, HCI was investigating media rich computing with the paradigm of computer mediated interaction. Interactive multimedia was the focus of attention. More recently, at the turn of the century, HCI was about social computing and its associated paradigm: community mediated interaction (see also Rauterberg, 2004). The HCI research field investigated applications such as Computer Supported Cooperative Work (CSCW), and the Internet (on line communities). Nowadays, with mobile, portable and ubiquitous technology, HCI is looking at more personalised and intimate interaction (Nakatsu et al., 2005).

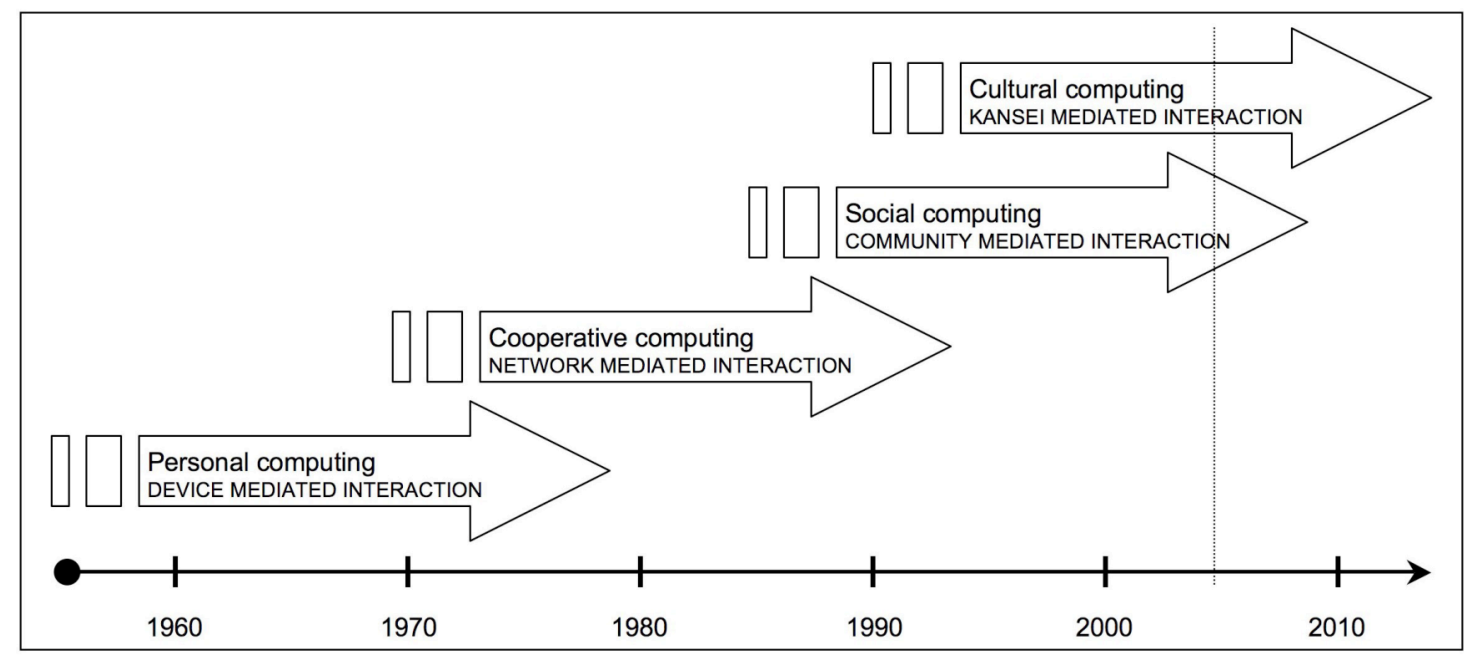

Fig. 1. From Personal to Cultural Computing

Several paradigms have emerged in recent years for the future directions of HCI: ubiquitous, nomadic, mixed-reality computing, and so on. In general all these new directions have some common properties. These are: (1) the disappearing computer; (2) from conscious to unconscious interaction (Rauterberg, 2006); and (3) the building of communities. A computer is not more the centre of interest or the focus of attention of the user. It is the running applications and the benefits and affects these have on the user that matter. The benefits and effects on the user are not limited to the domain of the application but have been extended to include all aspects of interest to the user. In this perspective, cultural computing has emerged as an interesting direction. A direction we are interested to investigate. 


\subsection{Cultural Computing}

Culture is the integration of human behaviour that includes attitudes, norms, values, beliefs, actions, communications and groups (ethnic, religious, social, etc.). These are exchanged between members of the same culture in an implicit way and with members of different culture in an explicit way (see Fig. 2).

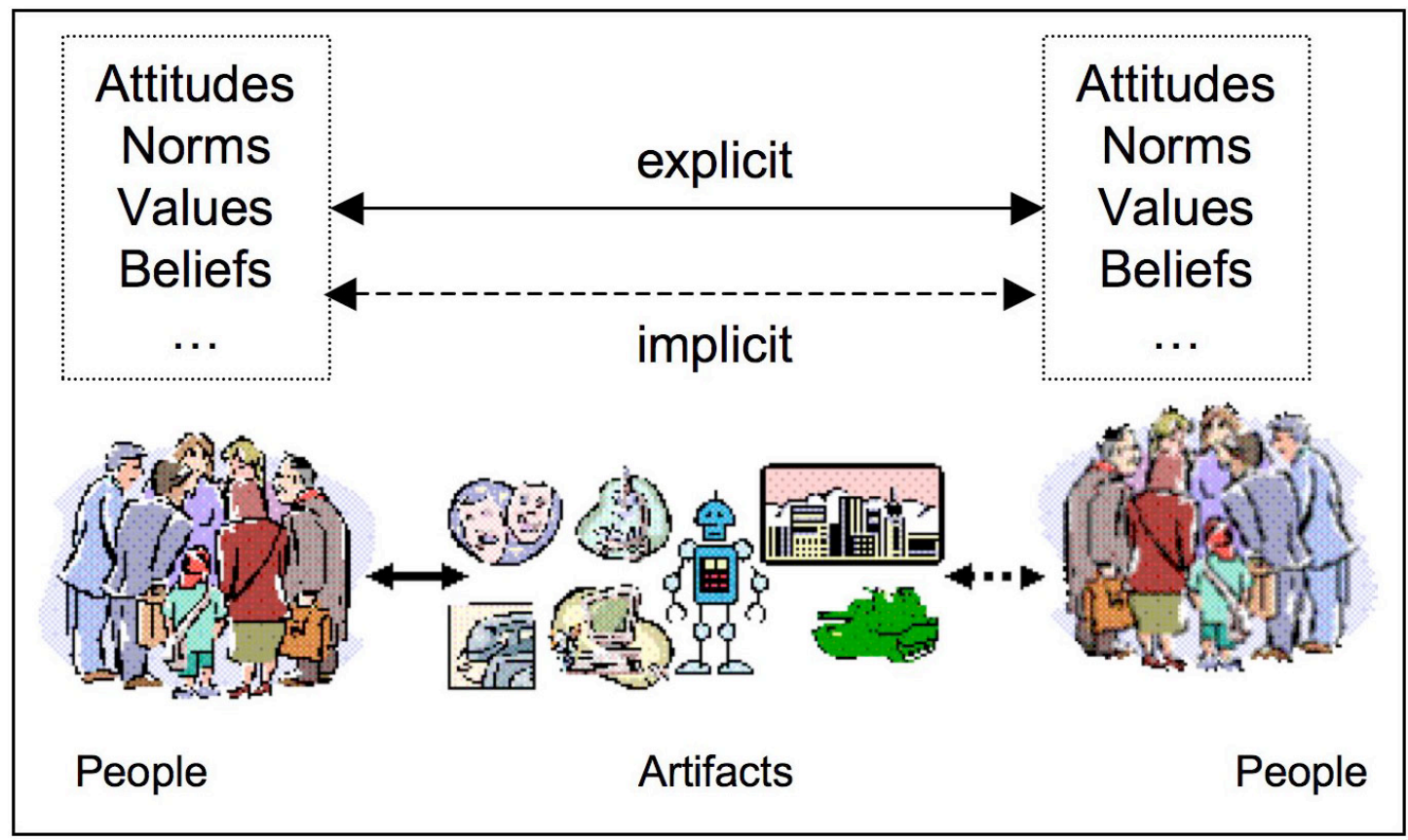

Fig 2. Culture is determined partly by explicit (straight lines) and mainly by implicit communication (broken lines) about attitudes, norms, values, beliefs, etc. Different cultures are characterized by their social behaviour pattern and produced artefacts.

Tosa et al (2005) think of Cultural Computing as a method for cultural translation that uses scientific methods to represent the essential aspects of culture (see also CCP, 2004). Including cultural concepts that heretofore have not been the focus of computing, such as mental images of Eastern thought and Buddhism, and the Sansui paintings, poetry and kimono that evoke these images, they projected the style of communication developed by Zen schools over hundreds of years into a world for the user to explore - an exotic Eastern Sansui world: the ZENetic computer. Through encounters with Zen Koans and haiku poetry, the user is constantly and sharply forced to confirm the whereabouts of his or her self-consciousness. Salem and Rauterberg (2005a) discuss the relationship of cultural computing and entertainment. What would be an equivalent system for Cultural Computing in the West? Nakatsu et al (2006) try to give a future direction in form of 'Kansei Mediation' to transform societies towards Enlightenment. In one astonishing, short period - the ninth century BCE - the peoples of four distinct regions of the civilized world created the religious and philosophical traditions that have continued to nourish humanity into the present day: Confucianism and Daoism in China; Hinduism and Buddhism in India; monotheism in middle east; and philosophical rationalism in Greece. 'Monotheism' and 'philosophical rationalism' is the religious and cultural foundation of the occident. Kant (1784) gave a first answer to the question, "What is Enlightenment?" He indicated that the 'way out' that characterizes Enlightenment in the West is a process that releases us from the status of 'immaturity'; and by 'immaturity,' he meant a certain state of our will that makes us accept someone else's authority to lead us in areas where the use of reason is called for. Enlightenment is defined by a modification of the preexisting relation linking will, authority, and the use of reason.

Commedia Virtuale: Ben Salem (2005) has investigated face, hand and body expressions to be applied to avatars of a virtual environment to improve their communication capabilities and enrich and facilitate their perception by users of a virtual environment. He has based his work on inspiration from the world of theatre. In this perspective Commedia dell'Arte and Noh theatre have been the focus of his attention. He explored key features of Commedia dell'Arte namely improvisation, exaggerated gestures and expressive postures, and investigated how their adoption in the design of avatars are useful for 
Collaborative Virtual Environments. With the same objectives we looked at another theatre style, the Noh theatre. He investigated the variety of masks and the choreography. The outcome was a visual language for avatars made up of postures, gestures and appearances. He has concluded this investigation with the production of an experimental theatre play involving real and virtual actors and performing a classical plot from Commedia dell'Arte.

Pet Robots: There has been several investigations of various robotic systems for personal interaction: turning robots into pets and subjects of empathy. Developing a robot to nurture social and interpersonal skills to its user can be seen as a new dimension. The Tamagochi, Furby, micro-pets are examples that could be used as inspiration (Salem and Rauterberg, 2005b). The key issues they addressed were: (1) Rendering of emotion through postures and movements (Bartneck and Reichenbach, 2005), (2) effective human perception of the emotions expressed by the robot, (3) clear rules of engagement and social rules used by the human and the robot, (4) as natural as possible interaction between the user and the robot, and (5) real-time performance by the robot. Several modalities are available: body postures, body movements, simplified hand gestures, head movements, and the production of non-speech sounds. Social obligations and dialogue etiquette between the robot and his user will determine to a certain extent the experience the user will have of the robot. How the robot to be perceived is another major challenge. In our opinion to ensure a high level of empathy and the perception of real-like companionship, the robot should not be perceived as a tool, a pet or a cartoon creature but it should rather be perceived like an artificial being in between a pet and a human. This vision will be used as guideline for the robot(s) in ALICE (see next sections).

The Sensorama simulator: A system to stimulate the senses of the user with the aim of simulating an actual experience realistically (see Fig. 3). Various applications were proposed for this system. It was designed to be an arcade game, a training and educational tool. Essentially it is a system that let the user experience a ride on a motorbike in the most realistic way (remembering the system was developed in the 1960s). Rightfully, Sensorama is considered as the pre-cursor of many interaction developments such as multi-media and Virtual Reality. Although not explicitly described as such, we consider the Sensorama as the precursor of cultural computing. It implemented a range of media with the intent of simulating a realistic experience. To do so it included medias such as smells, wind, noises that are associated in the Western World with a bike ride in a town (Heiling, 1962).

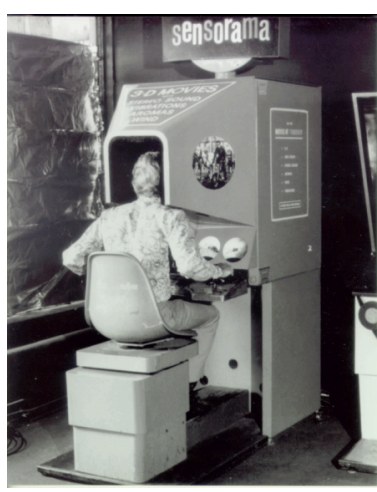

3.1. Picture of the system

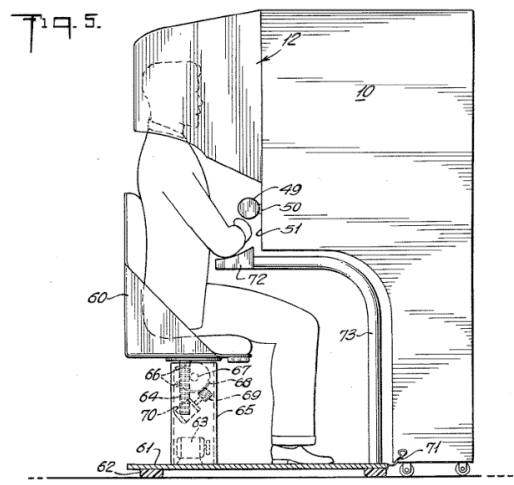

3.2. Drawing from the patent application

Fig 3. The Sensorama Simulator

Implementing similar systems for a range of applications rather than for the rendering of a single experience would be quite challenging. We advocate a different direction. One that relies on culture rather than experience.

\subsection{Implementing Cultural Computing}

Cultural computing (CC) is more than integrating a culture into the interaction. It is about allowing the user to experience an interaction that is closely related to the core aspects of his/her culture. In a way that let him/her engage with the interface using the values and attributes of his/her own culture. As such it is important to understand one's cultural values and how to render them during the interaction. As there are many cultures that we could investigate, there is a need to select a subset of cultures. In this paper we will focus on two representative sub-cultures, one from the Western world prevailing in England, and one from the Eastern World prevailing in Japan. 
To understand both cultures in a way that would fit the objectives of our interests, we have sought illustrative examples of both. Thus, we have investigated illustrative stories that are well known, accessible, classical in their respective cultures and relevant from the point of view of cultural computing. We also looked for stories that would be helpful in the understanding of the essential aspects of both Western and Eastern cultures.

The origin of Western culture stories can be traced back to Greek mythology. An example of Greek mythology is the Illiad and the Odyssey written by Homer in the $8^{\text {th }}$ Century BC. Illiad tells the story of the siege of the city of Illium during the Trojan War. The Odyssey describes the heroic journey back home from the Trojan war of Odysseus king of Ithaca. As for the Eastern Culture of Japan, the original works are the two mythological books Kojiki and Nihonshoki., completed in 712 and 720 respectively. Kojiki describes various myths and legends of Japan. It starts at the beginning of the world and ends at the reign of Empress Suiko. Nihonshoki is a compilation of the chronicles of Japan. Kojiki emphasise the mythical while Nihonshoki is more factual.

The historical mythologies could have been used, but within the context of our work they are rather complex in content, narrative and plot. We have selected less predominant stories but relevant none the less. These are for the Eastern culture: the story of The Ox herding attributed to a Ch'an master (circa 1200s), and the Journey to the West (1590). For the Western culture we have selected Alice in Wonderland by Lewis Carroll (1865), and Le Petit Prince by Antoine de Saint Exupery (1943). These stories help understand the underlying cultural value or question it. For the Eastern culture, the value dealt with is enlightenment, while it is orderly rational reason for the Western culture. In the next section we present an overview of these stories.

\subsection{Eastern Culture: Story of the 'Ox herding' (enlightenment)}

This short story has ten steps:

[1] Seeking the ox: Starting the journey, while being unaware that a dualist approach cannot lead to the understanding of the true nature of mind. There should not be a mind/body separation.

[2] Seeing the ox tracks: Although the ox is still not seen, the tracks confirm its existence, and lead to way to it. Through self discipline and training, it is possible to rediscover one's true self.

[3] Seeing the Ox: The path to enlightenment has been seen. It is about finding one's true self, through trial and errors (see Fig. 4.1).

[4] Catching the Ox: Although the ox has been seen, the difficulty now is to catch it (see Fig. 4.2).

[5] Herding the Ox: Kencho is finally obtained after a long period of disciplinary training. However, the Kencho attained is only a stepping stone towards Satori (see Fig. 4.3).

[6] Coming Home on the Ox's Back: The efforts paid off. The ox and the herder move together effortlessly. This shows the state in which one completely finds one's true self, that is, the state in which one obtains Satori (see Fig. 4.4).

[7] Ox is forgotten: The ox and the herder become one. Dualism has been overcome and the herder has no worldly attachments any more.

[8] Both Ox and self forgotten: The separation of reality from the mind is gone. Enlightenment is experienced and the mind has escaped.

[9] Returning to the source: Back to square one. The world carries on as always.

[10] Returning to help others: The enlightened has renounced all to selflessly help others (see Fig. 4.5).

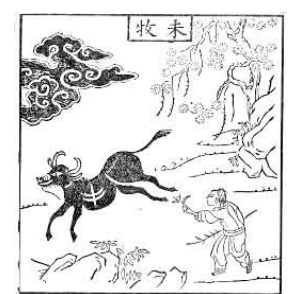

4.1. Step 3

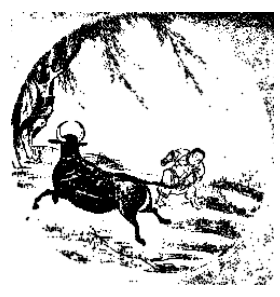

4.2. Step 4

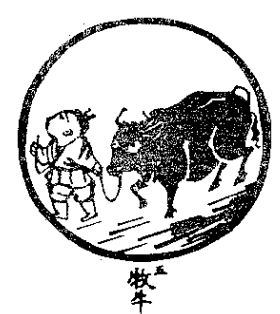

4.3. Step 5

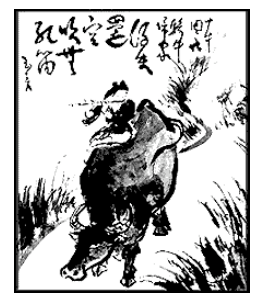

4.4. Step 6

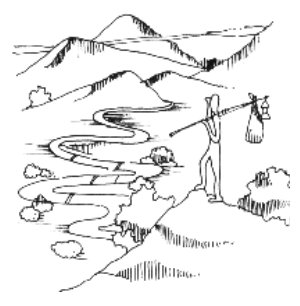

4.5. Step 10

Fig 4. Various representations of the Ox Herding Steps

The ten Ox Herding Pictures (Fig. 4) are an imagery of an illusion to be negated before a seeker can experience enlightenment. In these pictures, the ox symbolise the mind, while the herder the seeker. The illusion being that reality is separate from the mind (Budhanet, 2006). These metaphorical steps help one achieve Kencho and then Satori. Kencho is the initial awakening experience, while Satori is 
the more lasting experience of enlightenment. Both are however transitional compared with the Nirvana.

\subsection{Eastern Culture: Story of 'Journey to the West' and 'Dragon Ball'}

The Journey to the West is a Classical Chinese novel written circa 1590s. The story is a mythology describing the pilgrimage of a monk from China to India seeking religious texts called Sutras, and deals with ideals, redemption and atonement.

A modern version of this novel is the popular Dragon Ball Japanese Manga. It is loosely based the traditional Chinese tale. Dragon Ball is about the life and adventures of Son Goku, a monkey-tailed character, from his childhood all the way to being a grandfather. During his life he fights many battles and in the way becomes the strongest martial artist in the universe. The Dragon Balls are one component of the universe. They are magical spheres to summon a dragon and are scattered across the world.

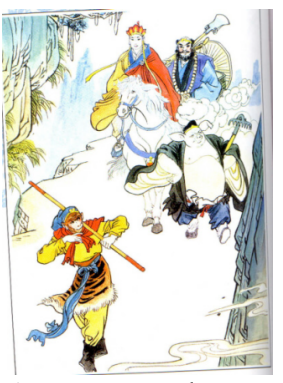

5.1. Journey to the West

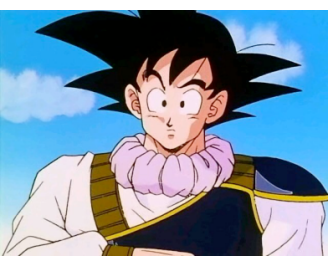

5.2. Son Goku (main)

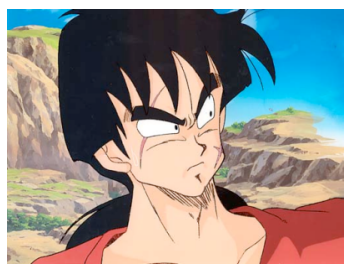

5.3. Yamcha

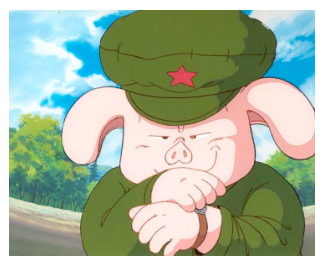

5.4. Oolong

Fig 5. Characters from 'Journey to the West' (5.1) and 'Dragon Ball' (5.2 - 5.4)

\subsection{Western Culture: Story of 'Alice in Wonderland'}

Alice adventures happen in a world of paradox, the absurd and the improbable (Wikipedia, 2006). The key aspects of Alice in Wonderland can be resumed in the following points: (1) a non linear non constant time flow; (2) a distortion of space and people; (3) a counter-intuitive, common sense defying heuristics. Alice's adventures are illustrative of English culture. Indeed English and Western culture in general are based on Monotheist religions (Judaism, Christianity, and Islam) which are concerned with certainty and absolutism: in the sense of absolute truth and certainty. Western culture is also based on Cartesian logic, analytical reasoning and a linear and constant flow of time.

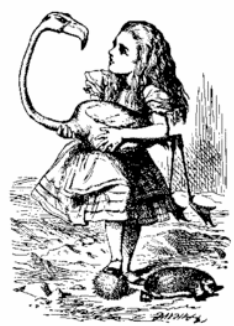

6.1. Alice

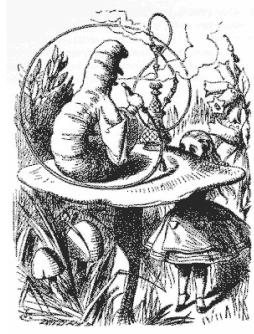

6.2. The Caterpillar

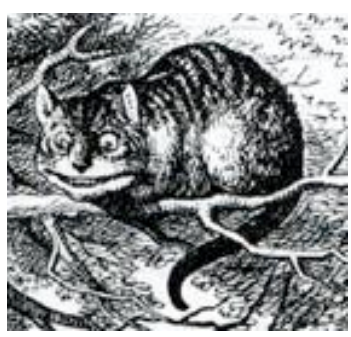

6.3. Cheshire Cat

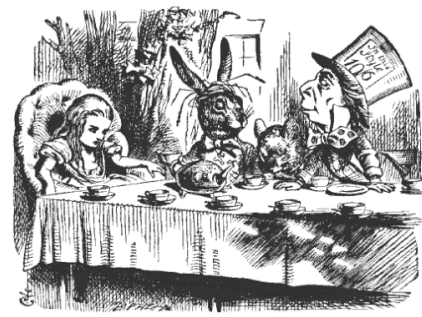

6.4. Tea Party

Fig 6. Characters from Alice Adventures in Wonderland

Alice in Wonderland can be used to give interesting examples of many of the basic concepts of adolescent psychology. Alice's experiences can be seen as symbolic depictions of important aspects of adolescent development, such as initiation, identity formation, and physical, cognitive, moral, and social development (Lough, 1983). Alice's adventures are deconstructive ${ }^{1}$ in nature and as such are directly challenging the strongly held belief of a linear, single track and sequential reality. 


\subsection{Western Culture: Story of 'Le Petit Prince'}

This story is mainly about wisdom and maturity. A young child (the 'prince') lives in a small asteroid where there are two volcanoes and a rose (see Fig. 7). One day the prince leaves to visit the rest of the universe. He visits several asteroids where he meets adults who are all caricature in their own ways:

The king, who reign over the stars by ordering them to do what they would anyway.

The conceited man, who wants to be admired by everyone.

The drunkard, who drinks to forget that he is ashamed of drinking.

The businessman, who is always busy counting the stars he is convinced he owns.

The lamplighter, who lights and extinguishes the lamp once a minute because he lives in a fast rotating asteroid.

The geographer, who makes maps of the world, does not trust things he hasn't seen with his own eyes but have never left his desk.

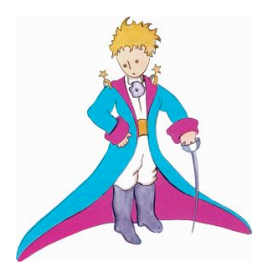

7.1. Petit Prince

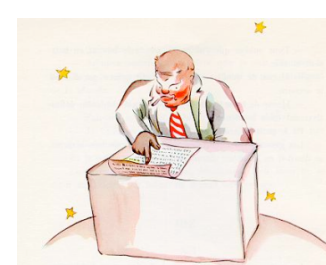

7.2. Businessman

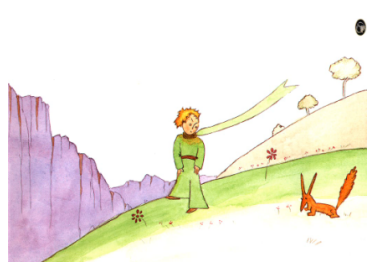

7.3. Fox

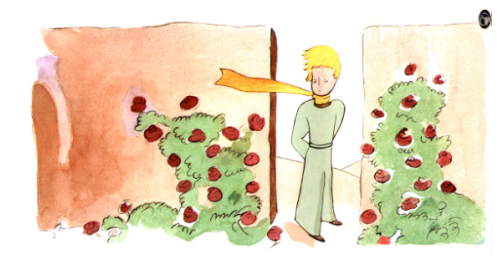

7.4. The Garden of Roses

Fig 7. Characters and Scenes from 'Le Petit Prince' $(7.1$ - 7.4)

The story is rich of famous quotes such as "Grown-ups never understand anything by themselves, and it is tiresome for children to be always and forever explaining things to them". The main character is sometimes very spontaneous and naïve, for instance in one statement he seems to disregard the need to wait for nature "I am very fond of sunsets. Come, let us go look at a sunset now". However The Little Prince is well aware of the importance of emotions and clearly states so when saying: "Here is my secret. It is very simple: One does not see well but with the heart. The essential is invisible to the eye". At other point the character is philosophical: "What makes the desert beautiful," says the little prince, "is that somewhere it hides a well".

Our aim is to use these selected stories as inspiration for the design of cultural computing. However we need first to describe the interaction paradigm we wish to use in the implementation of cultural computing.

\section{Implementing Cultural Computing}

Our approach is to create an interaction based on the cultural values highlighted in these stories. The drawback of this approach is the cultural dependency of the interaction developed (Nisbett et al., 2001). A westerner would understand and appreciate the implementation of an interaction inspired from 'Alice in Wonderland Adventures' or 'Le Petit Prince', but will be puzzled if s/he was presented with an interaction inspired from the 'Ox story' or 'The Journey to the West'. Similarly, an easterner would appreciate the second set and be confused by the first.

Although the cultural dependency is somewhat a drawback it has many advantages. Cultural computing allows for a much richer experience to be rendered. This is thanks to the complexity and depth of the semantics involved. There is also the advantage of higher bandwidth of information at the interface as symbolic meanings and implicit knowledge can be used. The interface is not limited to explicit messages and meanings. However, there is a challenge in finding culturally rich media that could be used to deliver our proposed system. We propose to rely on Kansei Mediation (KM) as a mean to deliver the necessary media and bandwidth rich interface.

\subsection{Kansei Mediation}

$\mathrm{KM}$ is a form of multimedia communication that carries non-verbal, emotional and Kansei information (Nakatsu et al., 2006). It is a combination of Kansei Communication and Kansei Media. In essence it is about exchanging cultural values efficiently and effectively. Kansei Communication is about sharing implicit knowledge such as feelings, emotions and moods. Kansei Media are the channels used to do so, such as voice tone and non-verbal communication. The integration of multiple, multimode and 
Kansei Media can enable a type of interaction that is neither biased towards cognition, nor biased towards awareness. This is what we call Kansei Mediated Interaction (KMI).

\subsection{KMI in the time domain}

Several cognitive functions can be ordered according to their life-span (see Fig. 8). KMI has the potential to stimulate and influence most of these functions. The cognitive functions are: reflexes, sensations, thoughts, dreams, emotions, moods, and drives.

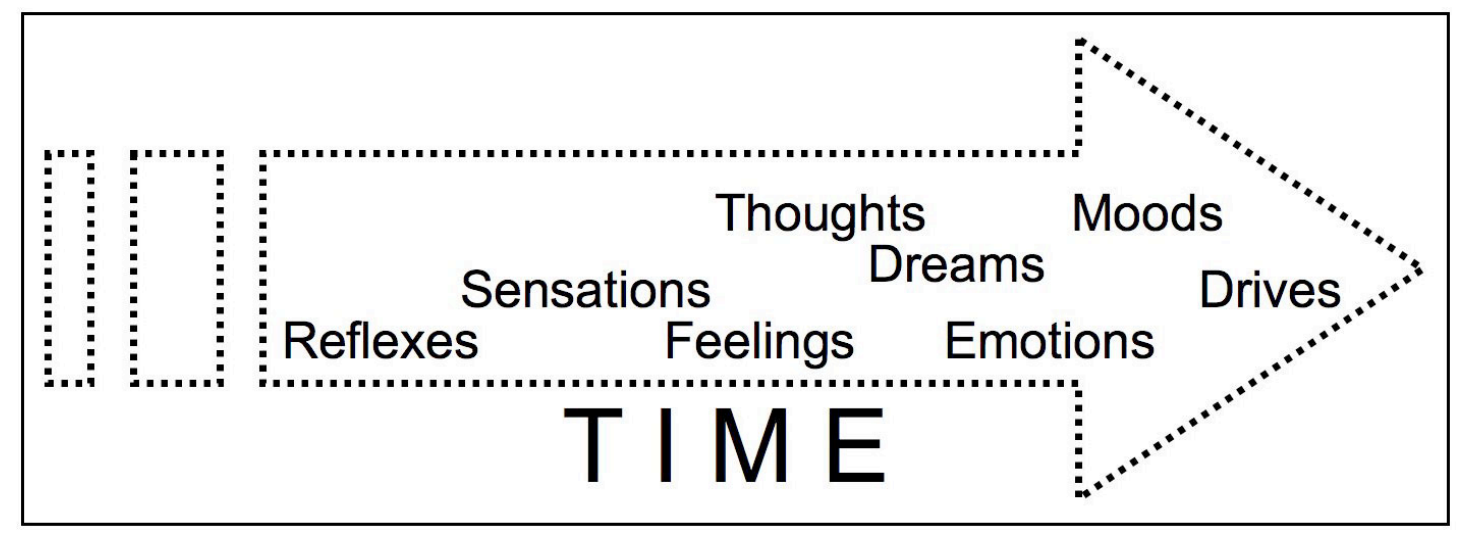

Fig 8. Time Scale of some cognitive functions

These different cognitive functions are linked to different control systems (bold black in Fig. 9) of our body. In turn, these links help us design the right interaction (italic in Fig. 9) through various body parts and control systems. To achieve KMI, one could implement the interaction using a combination of channels and medias (as the examples given to the right of Fig. 9).

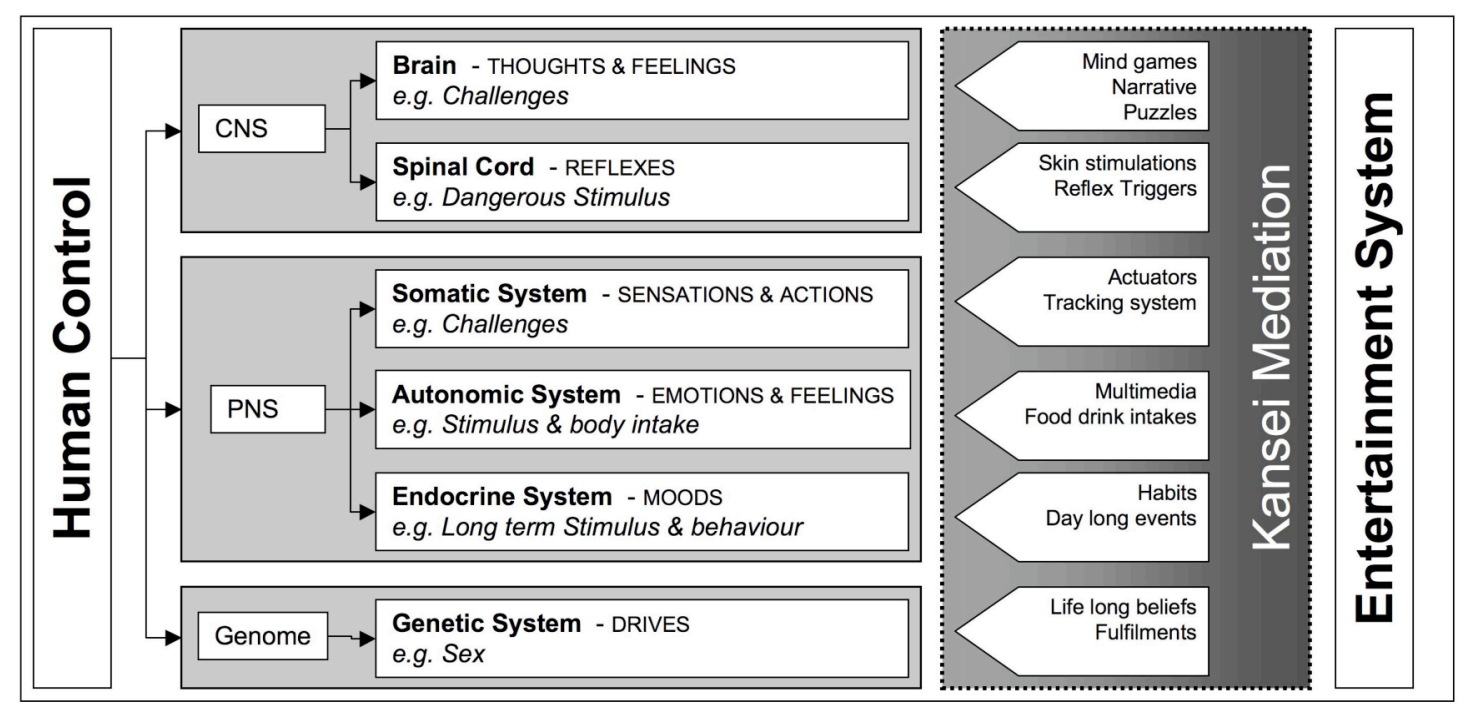

Fig 9. From human control mechanisms to entertainment [CNS: Central Nervous System, PNS: Peripheral Nervous System]

\subsection{Case Study: Alice in Wonderland}

The first interactive, but semi-immersive virtual reality system based on parts of 'Alice's Adventures in Wonderland' was developed at the Entertainment Technology Centre of Carnegie Mellon University. Pierce et al (1999) created a successful virtual experience based on a head-mounted display (HMD) to overcome some or all of the following problems: entering a virtual world is a jarring experience, people do not naturally turn their heads or talk to each other while wearing an HMD, putting on the equipment is hard, and people do not realize when the experience is over. In the Electric Garden at 
SIGGRAPH 97, they presented the Mad Hatter's Tea Party, a shared virtual environment experienced by more than 1,500 SIGGRAPH attendees. They addressed these HMD-related problems with a combination of back story, see-through head mounted displays, virtual characters, continuity of real and virtual objects, and the layout of the physical and virtual environments.

Our current project ALICE, is an augmented reality (AR) narrative with intelligent agents acting as characters who lead the user through virtual and real locations, moral choices and emotional states. The narrative is a surreal quest, sometimes funny, sometimes disturbing. The character White Rabbit (in our case a robot) introduces himself and joins with the user in a series of absurdist challenges. ALICE is an educational journey towards the user's heart's desire, designed to provoke self-reflection on a number of unconscious cultural issues: logic and reasoning, self and ego, bullying and trusting others; selfishand selfless-ness; and sublimating pleasure. The user is given the opportunity to occupy and experience any of these mental and emotional positions. This will be achieved in line with the Alice in Wonderland plot (albeit shortened).

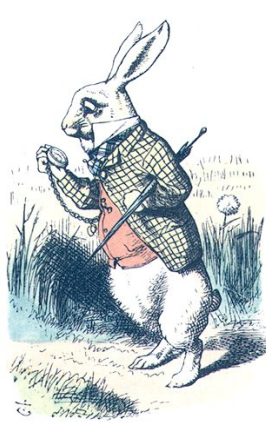

10.1. Stage 1

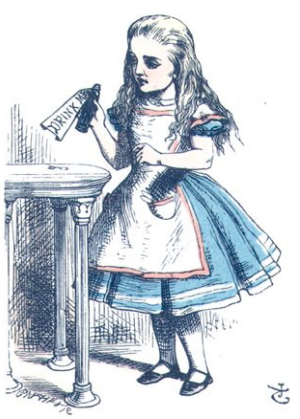

10.2. Stage 2

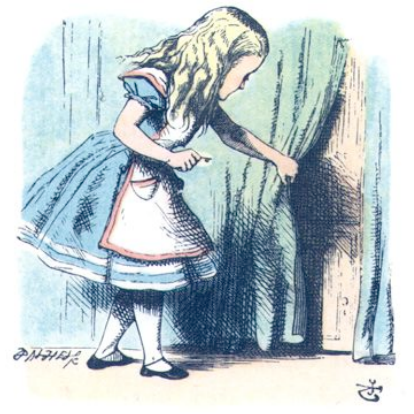

10.3. Stage 3

Fig 10. The 3 stages we plan to implement

Stage-1: To simulate the 'Down the Rabbit Hole' experience (see Fig. 11), the entrance is a spiral tube slide that ends in the projection cave of stage-2. The spiral tube slide includes visual and audio projections throughout the sliding experience. The rabbit-hole goes straight on like a tunnel, and then dips suddenly down, so that the user has no opportunity to stop him- or herself. Either the well is very deep, or the fall is very slow, for the user has plenty of time as he slides down to look about him and to wonder what is going to happen next.

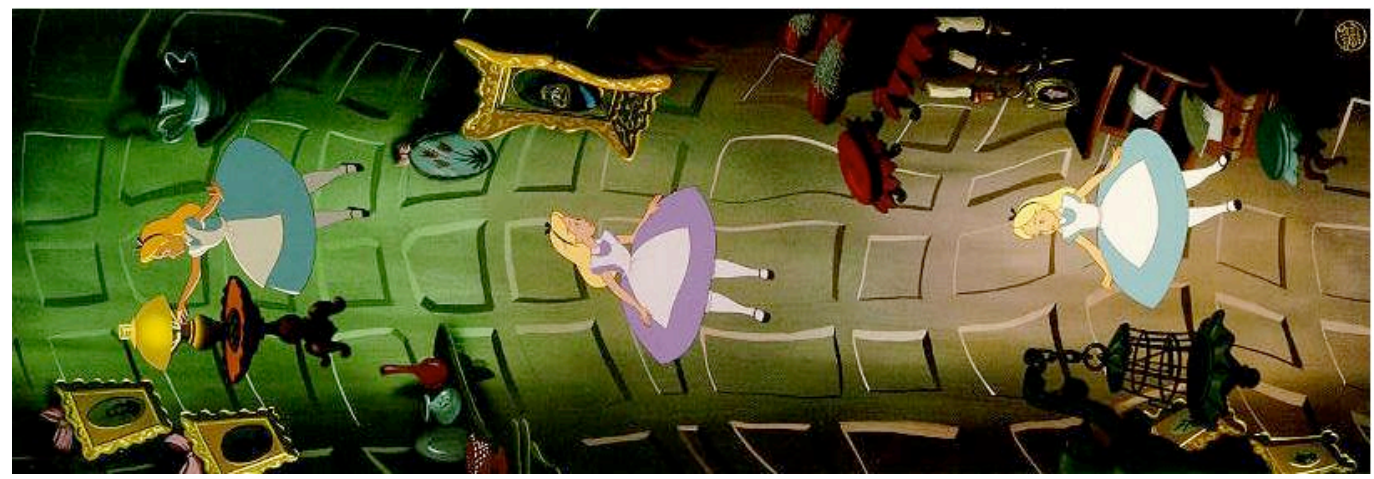

Fig 11. Alice falling down the rabbit hole

Stage-2: The end of stage-1 is inside a cave with four walls of which three are projection walls. Through one of the projection walls the user is able to go through (e.g. based on Fog Screen Technology (2006) or just a mechanical solution) to continue the experience. Inside the cave the user has access to two tangible devices: 'nibble' and 'drink me' (see Fig. 12). Both devices are hanging from the ceiling to control their physical height. With these two devices the user can interact with the environment to adjust the size: shrinking or growing. In case of proper sizing the exit door will be opened to leave the cave. The character 'White Rabbit' in form of a pet robot will accompany the user to provide help. The tangible input devices will have an orientation sensor (e.g. VTT's SoapBox or a cheaper replacement) so that the amount of 'drinking' or 'eating' can be measured to control the environment. 


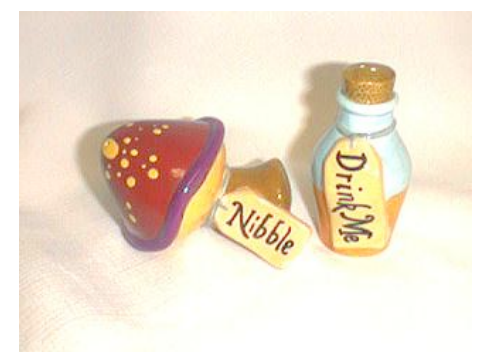

Fig 12. Two tangible input devices 'Nibble' and 'Drink Me'

Stage-3: To talk to the Cheshire Cat a painted wall with a back projection area inside this painting is provided (see Fig. 13). In front of this tree a sensitive floor is laid out. Depended on the position of the user, the reaction of the Cat is different (e.g. visible or disappearing). A particular dialog will challenge the user to reflect on logic and reasoning.

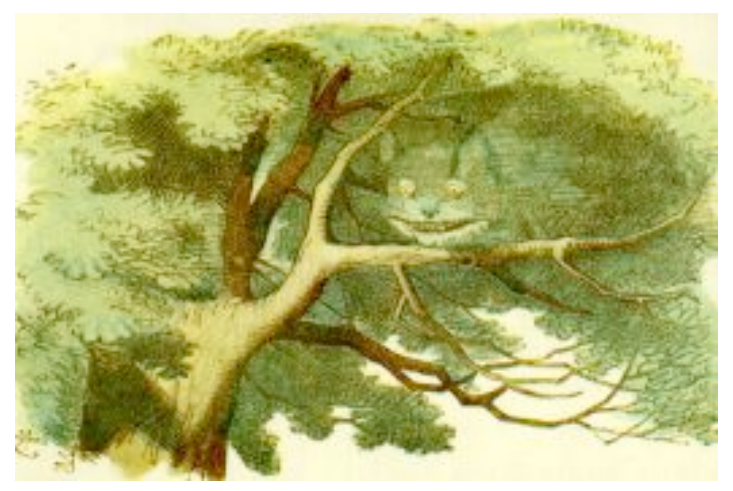

Fig 13. Talking to the Cheshire Cat

Stage-4: The next stage of the ALICE experience would be the 'Mad Hatter's Tea Party' in which virtual characters and objects are mixed with real objects and agents. The Helio (2006) display technology will be investigated for projecting the virtual objects on the table. Cavazza et al (2004) describe a new approach to the behaviour of 3D environments that supports the definition of physical processes and interactive phenomena. The work takes as a starting point the traditional event-based architecture that underlies most game engines. These systems discretise the environments' Physics by separating the objects' kinematics from the physical processes corresponding to objects interactions. This property can be used to insert a new behavioural layer, which implements AI-based simulation techniques. They introduce the rationale behind AI-based simulation and the techniques they use for qualitative Physics, as well as a new approach to world behaviour based on the induction of causal impressions. This approach has implications for the definition of complex world behaviour or nonstandard physics, as required in creative applications

\section{Conclusions}

In this paper we have attempted to define and explain a novel concept we call Kansei Mediated Interaction (KMI) and we have tried to illustrate an implementation of KMI in entertainment. In our opinion Kansei Mediated Entertainment (KME) is a promising development because it allows for the delivery of both explicitly and implicitly rich experiences. KME is also of relevance nowadays with the acknowledgment of emotions and feelings as important component of our cognitive functions.

We have focused on our current implementation of KME with the project ALICE, however, for the other stories implementation of $\mathrm{KME}$ is also feasible. We hereby outline a possible direction for implementation: (1) Ox Herding and Journey to the West: These stories are metaphors. The plot is not based on a principal character performing some actions. These stories are about the discovery of deeper meanings and values for events and other characters. Therefore its implementation is unlike the Alice in Wonderland implementation. It is translated into the interaction iterations akin to interface choreography. (2) Le Petit Prince Adventures relate to the rediscovery of one's lost personality characters when growing from childhood and entering adulthood. The author is inviting us to re- 
discover ourselves and let the child in every one of us express him/herself again. A possible implementation is in the form of an environment where the interaction is based on play and other children related activities.

Finally, we hope to have raised the awareness of Kansei media and communication in the field of entertainment and demonstrated through our proposed KME of the significant potential a Kansei approach could have on entertainment.

\section{Acknowledgement}

This paper was written as part of a long-term cooperation between the School of Science and Technology, Kwansei Gakuin University, Japan and the Department of Industrial Design, Eindhoven University of Technology, The Netherlands. We are grateful for the sponsoring of Microsoft Research Europe.

\section{References}

Bartneck C, Reichenbach J (2005). Subtle emotional expressions of synthetic characters. International Journal of Human-Computer Studies, 62(2), 179-192.

Cavazza M, Hartley S, Lugrin JL, Libardi P, Le Bras M (2004). New Behavioural Approaches for Virtual Environments. Lecture Notes in Computer Science, vol. 3166, pp. 23-31.

CCP (2004) Cultural Computing Program, http://www.culturalcomputing.uiuc.edu/

FOGSCREEN (2006), http://www.fogscreen.com/

HELIO (2006) Display, http://www.io2technology.com/

Heiling M (1962). Sensorama Simulator, US Patent 3,050,870.

Kant I (1784). Beantwortung der Frage: Was ist Aufklärung? Berlinische Monatschrift, 2, 481-494.

Lough GC (1983). Alice in Wonderland and cognitive development: teaching with examples. Journal of Adolescence, 6(4), 305-315.

Nakatsu R, Rauterberg M, Vorderer P (2005). A new framework for entertainment computing: from passive to active experience. Lecture Notes in Computer Science, vol. 3711, pp. 1-12.

Nakatsu R, Rauterberg M, Salem B (2006). Forms and theories of communication: from multimedia to Kansei mediation. Multimedia Systems, 11(3), 304-312.

Nisbett RE., Peng K., Choi I. \& Norenzayan A. (2001). Culture and sSystems of thought: holistic versus analytic cognition. Psychological Review, 108(2), 291-310.

Pierce JS, Pausch R, Sturgill CB, Christiansen KD (1999). Designing a successful HMD-based experience. Presence, 8(4), pp. 469-473.

Rauterberg M (2004). Positive effects of entertainment technology on human behaviour. In: R. Jacquart (ed.), Building the Information Society (pp. 51-58). IFIP, Kluwer Academic Press.

Rauterberg M. (2006, in press). From Personal to Cultural Computing: how to assess a cultural experience. In: Proceedings of the $4^{\text {th }}$ Usability Day (9. Juni 2006), Applied University Vorarlberg, Dornbirn, Austria. Pabst Science Publisher.

Salem B (2005). Commedia Virtuale: from theatre to avatars. Digital Creativity, 16(3), 129-139.

Salem B, Rauterberg M (2005a). Aesthetics as a key dimension for designing ubiquitous entertainment systems. In: M. Minoh \& N. Tosa (eds.) The 2nd International Workshop on Ubiquitous Home-ubiquitous society and entertainment. (pp. 85-94) NICT Keihanna and Kyoto.

Salem B, Rauterberg M (2005b). Power, Death and Love: a trilogy for entertainment. Lecture Notes in Computer Science, vol. 3711, pp. 279-290.

Tosa N, Matsuoka S, Ellis B, Ueda H, Nakatsu R (2005). Cultural Computing with context-aware application: ZENetic Computer. Lecture Notes in Computer Science, vol. 3711, pp. 13-23.

The ox herding pictures were taken from the following websites:

Fig $3 \mathrm{http}: / / \mathrm{www}$. sacred-texts.com/bud/mzb/oxherd.htm,

Fig 4 http://www.hsuyun.org/Dharma/zbohy/VisualArts/OxHerdingPictures/oxherding2.html

Fig 5 http://oaks.nvg.org/wm2ra4.html

Fig $6 \mathrm{http}: / / \mathrm{www}$. donmeh-west.com/tenox.shtml

Fig 10: http://www.buddhanet.net/oxherd10.htm

The Alice in wonderland and the Petit Prince pictures were taken from Wikipedia 